\title{
HOJAS DE PARRA SALTO MORTAL EN UN ACTO
}

\author{
Jaime Vadell \\ José Manuel Salcedo \\ con poemas de Nicanor Parra
}

Nota del editor

M uchos de los poemas de Nicanor Parra tienen un definitivo cariz dramático, donde distintos personajes hablan desde sí mismos. No es de extrañar, entonces, que sus textos se hayan llevado al teatro al menos en cinco ocasiones, aunque con distinta suerte.

En 1970, bajo un título que hoy resulta profético, se estrenó Todas las colorinas tienen pecas o sólo para mayores de 100 años. En 1983, se adaptó, como monólogo, Sermones y prédicas del Cristo de Elqui. En 1992, el teatro de la Universidad Católica montó la traducción que Parra realizó de El rey Lear, que, como bien se sabe, es un texto que tiene tanto de Shakespeare como de Parra. En 1994, como parte de los homenajes a sus 80 años, se puso en escena una obra titulada Parranda.

JAIME VAdELl (Santiago, 1940). Actor chileno y director teatral. Su carrera en teatro, televisión y cine es prácticamente inabarcable. Para nombrar una de sus aristas: su carrera cinematográfica comenzó con Tres tristes tigres, de Raúl Ruiz, en 1968, y continúa hasta hoy, con Aurora y Santiago Violenta, ambas películas de 2014.

José Manuel Salcedo (Santiago, 1940). Actor chileno y publicista. En su juventud dedicó sus energías al teatro, la televisión y el cine. Más tarde, desarrolló una labor publicitaria, con especial énfasis en la comunicación política. 
Hojas de Parra / Salto mortal en un acto, obra que a continuación Estudios Públicos tiene el gusto de publicar, se estrenó en 1977, en un país que vivía en el período más duro de la dictadura, y no tuvo más de once funciones antes de que la carpa donde se desarrollaba fuera clausurada y, más tarde, incendiada por "desconocidos".

La obra nació de la iniciativa de los actores Jaime Vadell y José Manuel Salcedo, quienes, antes de cumplir los 40 años de edad, se habían separado del teatro Ictus por diferencias artísticas, para fundar la compañía La Feria. Ambos ya habían conocido a Parra cuando realizaron una adaptación del poema "Un hombre" para La Manivela, programa de televisión creado por el Ictus durante la Unidad Popular y que había tenido un breve regreso a la pantalla entre 1974 y 1975 , gracias a UCV Televisión. En 1976, con la idea de hacer un teatro más accesible y popular, Vadell y Salcedo regresaron donde Parra, quien puso a su disposición su poesía publicada hasta el momento y les facilitó también algunos poemas inéditos. Vadell y Salcedo, junto con Susana Bomchil - actriz y quien terminaría desarrollando la dirección de arte de la obra-, entonces trabajaron a toda prisa en un primer borrador del montaje. Le mostraron una primera versión a Nicanor Parra, que le gustó poco según recuerdan Vadell y Salcedo, pero luego llegaron a una solución que lo satisfizo.

Después de un frenético trabajo de pocos meses, Hojas de Parra - título usado, posiblemente, por primera vez, mucho antes del libro homónimo de 1985 - tuvo su función de estreno el 18 de febrero de 1977. Se montó en una carpa de circo de dos mástiles, levantada en un sitio baldío en la esquina de Nueva Providencia y Marchant Pereira, un espacio que permitía recibir a cerca de ochocientas personas por función. Se escogió este escenario porque la obra se desarrolla, justamente, en un circo, que ha llegado a tal nivel de pobreza que, por un lado, comienza a ser invadido por el cementerio vecino y, por otro, debe arrendar su espacio para actividades de todo orden, como las de un candidato presidencial llamado Nadie o una reunión de la Sociedad de Mantención del Recuerdo Eterno de los Poetas Muertos y Vivos. Bajo un aparente caos, durante una hora y media y con el despliegue de cerca de 25 actores, la obra combinaba actos propiamente circenses, como un trapecista y un número de payasos, con poemas de Parra, apuntes cómicos y diversos saltos lógicos. La obra incluso tiene un texto —utilizado 
durante la romería a la tumba del poeta desconocido- que no es de autoría de Parra pero lo simula ser, efecto explícitamente buscado por Salcedo y Vadell. En suma, Hojas de Parra fue un montaje carnavalesco, cómico y con no poca parodia, que buscaba hacer reír, pero también aludir a la situación política y social bajo la dictadura.

La obra, a muy poco andar, gracias al boca a boca se convirtió en un éxito de público, pero este éxito también contribuyó a su fin. El 28 de febrero de 1977, diez días después de su estreno público, el diario La Segunda, bajo el titular "Obra teatral critica política del Gobierno", publicó en su portada una crónica con un evidente ánimo denunciatorio, donde calificó el montaje como "la más increíble e insolente crítica contra nuestro proceso, contra el 11 de septiembre y contra quienes en un supremo esfuerzo sacaron a este país de las garras del marxismo, y lo encaminan por la senda del progreso y la paz". En otro pasaje, la crónica señaló: "Cada pasaje de la obra tiene un trasfondo político y una clara intención, no de crítica constructiva sino de crítica sibilina, usando para ello rebuscados simbolismos que para el espectador corriente es difícil descifrar y captar qué es lo que se busca con ellos".

De acuerdo con Vadell y Salcedo, la misma tarde en que apareció esta crónica el Servicio Nacional de Salud clausuró la carpa debido a faltas concernientes a baños y agua sanitaria. Subsanadas estas faltas, el Servicio Nacional de Salud encontró otras razones para insistir en la clausura. Solucionados sus nuevos requerimientos, la Municipalidad de Providencia, que había prestado el terreno baldío para instalar la carpa, les revocó el permiso para usarlo. En la espera para reunirse con el alcalde, la madrugada del 12 de marzo, durante las horas en que entonces regía el toque de queda, la carpa fue quemada. Nunca se descubrió a los culpables del atentado. En cualquier caso, el mensaje fue claro. Pese a que había seguros comprometidos, la obra no volvió a montarse y su texto permaneció inédito hasta hoy.

Esta obra de teatro se rescató desde los archivos de la Biblioteca de Teatro, Cine y Televisión de la Pontificia Universidad Católica, gracias a las pesquisas del editor Adán Méndez, y se publica con el beneplácito de los autores. En la transcripción hecha de los poemas de Parra, se mantuvo la puntuación y el uso de mayúsculas y minúsculas del mecanografiado original. 


\section{HOJAS DE PARRA SALTO MORTAL EN UN ACTO}

La acción transcurre en una carpa de circo, con pista central y dos accesos enfrentados, correspondiendo uno de ellos al ingreso del público y el otro a "la boca del tony" o ingreso de artistas. En otras palabras, un circo instalado como tal.

Al iniciarse el espectáculo, entra la banda del circo, toma ubicación en su plataforma y comienza a afinar sus instrumentos. Desde la misma boca del tony ingresan, casi simultáneamente con la banda, dos obreros; traen unas cruces blancas que van instalando, cubriendo, poco a poco, ese sector. La actividad de estos obreros se realizará casi sin interrupciones a lo largo de todo el espectáculo, de forma tal que las cruces van a ir invadiendo progresivamente todo el local: pista, pasillos, etcétera.

Cuando los obreros están instalando la cuarta cruz, entra, por el acceso de público, el empresario del circo para iniciar su ensayo. Se dirige hacia donde están los obreros trabajando y se inicia un diálogo a voz normal y sin el uso de la amplificación, de forma tal que no se escucha lo que hablan, aunque queda de manifiesto la molestia del empresario por la actividad extraña que estos obreros están realizando allí. Todo lo anterior se realizará con la luz normal de la sala. El empresario viste con chaqueta de lamé y corbata mariposa.

EMPRESARIO: (Toma un micrófono de mano, por lo tanto esto se escucha en toda la sala.) Bueno, y idónde está el responsable de esto? (Los obreros hacen un gesto de que no saben.) Bueno, ya. En cuanto llegue dígale que venga a hablar conmigo. Yo tengo que hacer mi ensayo de todas maneras. Tengo una serie de números nuevos aquí. (La banda comienza a afinar sus instrumentos y a tocar algunos compases.) Yo no puedo hacer la función sin ensayar primero. (Dirigiéndose a la banda.) Ya, comenzamos no más: Aquí yo hago la presentación, ustedes me acompañan de atrasito. (La banda toca la música como en una función real. Gran acorde inicial.) El Gran 
Circo La Feria tiene el agrado de presentar su espectáculo 1977 con las más grandes atracciones... el malabarista XXX... (Un redoble se tocará entre cada anuncio.) ...el Médico a Palos; el Verdugo Imaginario; el Trapecista XXX; Hamlet, príncipe de Dinamarca; el Hombre Más Hambriento del Mundo; el equilibrista XXX; el Fantasma que Recorre Europa; el Cesante Fortuito y la participación de los payasos Matita, Polito y Pitito. (A la banda.) Cuando yo digo esto último ustedes rompen con la marcha del desfile, ¿entendido? (Hacia afuera.) ¿Están listos para el desfile?

DESDE FUERA: ¡Sí!

EMPRESARIO: ¡YYa!, elejota entonces... y la participación de los payasos Matita, Polito y Pitito. (El empresario toca su silbato.)

Parte la banda a todo dar tocando la marcha del desfile. Antes de que ingrese el desfile aparece desde la calle un hombre gritando. Este viste un vistoso terno, tal vez brillante acero y un sombrero de pita con una ancha cinta a la manera de la afectada elegancia de las películas norteamericanas de los años sesenta.

HOMBRE:

¡Oiga ¡ ¡Señor! ¡Eh, señor! ¡Un momento! ¡Un momento, por favor! ¡Un momentito!

EMPRESARIO: (Detiene la banda.) ¿Qué pasa, hombre? ¿No ve que estamos ensayando?

HOMBRE: $\quad$ Sí, perdón, un momentito no más. Es que quería pedirle un favor.

EMPRESARIO: $\quad$ Bueno, pero es que...

Debido a la interrupción del ensayo, entra toda la troupe del circo, vestida en ropa de calle y van siguiendo el diálogo posterior.

HOMBRE: No, si es una cosa corta. Le conviene.

EMPRESARIO: A ver, diga, hombre ¿de qué se trata? Pero que sea corto... 
HOMBRE:

EMPRESARIO:

HOMBRE:

EMPRESARIO:

HOMBRE:

EMPRESARIO:

HOMBRE:

EMPRESARIO:

HOMBRE:

EMPRESARIO:

HOMBRE:

EMPRESARIO:

HOMBRE:

EMPRESARIO:

HOMBRE:

EMPRESARIO:

HOMBRE:
El problema es que necesitamos un local en este sector.

Ah, ¿y?

Habíamos pensado que esta carpa sería ideal.

Ah. Y, ¿para cuándo la necesitaría usted?

Ahora. Ahora, altiro... Prácticamente altiro...

Ah, no, eso sí que no va a ser posible. ¿No ve que nosotros tenemos que hacer nuestro ensayo?

Pero si es una cosa corta... No más de quince minutos. Usted puede suspender su ensayo por un rato.

Ah, no, por ningún motivo, el ensayo es sagrado. ¿No ve que si las cosas no salen bien, después el público no viene y uno vive del público?

Bueno, por último, suspende la función...

La función está anunciada, señor, esto no es chacota. Siempre la gente cree que estas cosas de los artistas son chacota. Y no son chacota, son tan serias como cualquier otra.

Haga su función mañana, pues, señor...

¿Usted está loco? ¿Usted cree que yo vivo de bolitas de dulce?

Precisamente de eso quería hablarle.

¿Cómo así?

Bueno, yo dispongo de una suma para compensarlo por esta molestia.

Ah... y... ¿como cuánto sería?

Bueno, yo había pensado en...

El empresario lo retira hacia otro lado y lo obliga a hablarle al oído

EMPRESARIO: $\quad$ Ahhhh... ¿y no podría ser...? (Le dice otra cifra al oído.)

HOMBRE: $\quad$ ¡Conforme!... (Le paga con un fajo de billetes al empresario.) Pero en ese caso tendría que poner la banda a mi disposición. 
EMPRESARIO: (Pasándole gran parte del dinero a uno de los tonys y dejándose algunos billetes para él.) Toma, repárteselos a la gente (El tony lo hace mientras el empresario sigue hablando con el hombre.) Pero ningún problema, señor. No faltaba más. Si esto no es ninguna novedad para nosotros.

HOMBRE: Gracias.

EMPRESARIO: Nosotros arrendamos la banda, también arrendamos la carpa o parte de la carpa o toda la carpa o también arrendamos la carpa con el personal o el personal sin la carpa o parte del personal o todo el personal... Usted sabe, hay que rebuscárselas como se pueda.

HOMBRE: $\quad$ Ah, magnífico, en ese caso yo los ocuparía a todos...

EMPRESARIO: $\quad$ Conforme, no más...

HOMBRE: Claro, porque yo necesito manifestantes, gente que grite, que me avive la cueca.

EMPRESARIO: Bueno, y ¿de qué se trata este asunto?

HOMBRE: No, de nada, es una proclamación no más.... del candidato a la Presidencia.

EMPRESARIO: $\quad$ Ah... ¿y a la Presidencia de qué?

HOMBRE: No... a la Presidencia de la República, pues...

EMPRESARIO: iii¿Que?!!!

HOMBRE: $\quad$ No se preocupe, si es una cosa muy rápida. Es una proclamación relámpago.

EMPRESARIO: (Al trapecista.) ¡Ensaya tu número, no más, por mientras!

El trapecista se sube al trapecio y comienza a ensayar su número y lo seguirá haciendo durante toda la escena que sigue. El empresario se lleva al hombre aparte y le hablará sotto voce pero de manera que se escuchen sus palabras.

EMPRESARIO:

¡Cómo se le ocurre proponerme semejante huevada, hombre!

HOMBRE: $\quad$ Pero, ¿por qué? 
EMPRESARIO: ¿No sabe usted lo que es el receso político?

HOMBRE: Sí sé...

EMPRESARIO: ¿Entonces no ve que nos pueden cortar los cocos a todos aquí?

HOMBRE: $\quad$ Yo le aseguro que aquí no le cortan los cocos a nadie, señor.

EMPRESARIO: Vamos a terminar todos en una embajada.

HOMBRE: $\quad$ Pero si yo le digo que no pasa nada, hombre. Si esto se puede hacer. Se ha transmitido hasta por televisión.

EMPRESARIO: $\quad$ Puta, nos van a cagar, nos van a cagar, nos van a cagar....

HOMBRE: Bueno, ya, si tiene tanto problema, devuélvame la plata. Ya, ya, devuélvame la plata.

EMPRESARIO: $\quad$ Bueno, ya; bueno, ya, haga lo que quiera....

HOMBRE: $\quad$ Es que necesitaría algunas cosas yo aquí....

EMPRESARIO: Ya, ya, sí, sí, llévese la banda, llévese a toda la gente, haga lo que quiera, pero yo no sé nada... Nos van a cagar, nos van a cagar, nos van a cagar. (Al trapecista.) ¡Sigue ensayando tú no más! (Al hombre.) Bueno, y ¿qué necesita? (Al trapecista.) ¡No te vayai a sacar la cresta tú allá arriba!

HOMBRE: Necesitaría un estrado y algo para hablar... un micrófono.

EMPRESARIO: $\quad$ Bueno, ya, ya, no se preocupe, nosotros le vamos a hacer todo aquí. (Al personal.) ¡A ver, niños, acompañen al caballero!

El personal del circo sale por la boca del tony y la banda por la puerta de público.

HOMBRE: $\quad$ Ah, y póngame este liencito... (Le trae un lienzo que traía plegado.)

EMPRESARIO: (Se lo recibe mirando hacia otra parte.) ¡Con razón dicen que la necesidad tiene cara de hereje... (Medio llorando.) ¡Nos van a cagar! 
El hombre sale por la puerta del público. El empresario ayudado por alguien monta una especie de estrado y coloca el lienzo que dice: "La izquierda y la derecha unidas jamás serán vencidas". Mientras tanto, el trapecista realiza su número acompañado por un vals que se escucha por los parlantes.

Terminados estos arreglos, entra la comitiva con la banda y carteles que dicen: "Nadie for president" y con una bandera que simula la de U.S.A., con majorettes, plumeros de colores, etcétera. En un momento oportuno se produce un streaking. ${ }^{1}$ Comienza el discurso después de algunos gritos de protesta de los manifestantes motivados por la irrupción del hombre desnudo.

HOMBRE: $\quad$ Y ahora con Uds.

el abanderado del pueblo trabajador

Nadie en persona

Nadie en cuerpo y alma.

Con Uds.el enemigo mortal de los ricos

el salvador que todos esperábamos.

Todo lo que se diga está de más

Nadie es el hombre de la situación

el intérprete fiel de nuestros anhelos

el forjador del futuro de América.

Nadie es perfecto

Nadie es infalible

Nadie es profeta en su tierra

Nadie es juez y parte a la vez

Nadie lo sabe todo

Nadie está por encima de sí mismo

Nadie está a salvo de una pulmonía

Nadie puede decir no moriré

Nuestra confianza en Nadie es absoluta

Nadie rebajará los impuestos

Nadie degollará la burocracia

Nadie le pondrá coto al abuso

${ }^{1}$ Streaking es el acto de correr desnudo en un lugar público (N. del E.). 
Nadie le pondrá fin a la inflación

Nadie reducirá los gastos públicos

Nadie equilibrará la balanza de pagos

Nadie respetará nuestros derechos

Nadie es capaz de vencer a los rusos

Nadie nos librará del comunismo

Nadie merece la silla de Lincoln.

Todo el mundo de pie:

¿Quién es el abanderado del pueblo?

Nadie

¿Quién es el campeón de los humildes?

Nadie

¿Nuestra primera y última esperanza?

Nadie

¿Nuestra razón de ser en el mundo?

Nadie

¿Nuestro pan

nuestra carne

nuestro vino?

Nadie

¿El plasmador de nuestros ideales?

Nadie

¿El cancerbero de nuestra cuenta bancaria?

Nadie

¿El marido de todas las mujeres

y la mujer de todos los maridos?

Nadie

¿El amigo de China Popular?

Nadie

¿El terror de la Unión Soviética?

Nadie.

¿El domador de la fiera fascista?

Nadie

¿El protector de doncellas y viudas?

Nadie

¿El faisán de la paz 
el plafagonio de la Democracia?

Nadie

Entonces todos a votar por Nadie.

Como dijo McGovern

lo que le falta a América es un líder

que le devuelva la confianza en sí misma

y la saque del fango de Watergate.

Alguien que no le deba nada a la CIA

Alguien ajeno a la General Motors

Alguien que no pertenezca a la mafia

Alguien que venga de lo más hondo del pueblo:

un leñador - un sastre - un manicero.

Sacerdotes católicos, no

Fabricantes de drogas, no

Futbolistas irresponsables, tampoco

¡Nadie en persona! ¡Nadie en cuerpo y alma!

A ver, a ver, con todas las fuerzas de nuestros

[pulmones

¿Quién hará realidad nuestros sueños?

Nadie

¿Quién solucionará nuestros enigmas?

Nadie

¿Quién sacará la cara por nosotros?

Nadie

¿Quién realmente dice lo que piensa?

Nadie

¿Quién realmente piensa lo que dice?

Nadie

¿Quién subirá los sueldos y salarios?

Nadie

¿Quién bajará los arriendos?

Nadie

¿Quién le torcerá el cuello al cisne rubendariano?

Nadie

¿Quién incrementará la producción? 
Nadie

¿Quién reestructurará la educación?

Nadie

¿Quién acelerará la extremaunción?

Nadie

¿Quién le pondrá las peras a cuatro a la estatua de la Libertad?

Nadie

¿Quién aglutinará los Sindicatos?

Nadie

¿Quién desmantelará los Sindicatos?

Nadie

¿Quién refaccionará la Casa Blanca?

Nadie

¿Quién pondrá a Dios en el lugar que le

[corresponde?

Nadie

¿Quién pintará de rojo los copihues?

Nadie

¿Quién pintará los copihues de rojo?

Entonces todos a votar por Nadie

Nadie al poder

Nadie a la primera magistratura de la República

Nuestro líder ha dicho claramente

que nos encontramos ante el acontecimiento

[más grande del siglo

Nuestro líder ha dicho textualmente

Devolveré el Canal de Panamá (Aplausos.)

Retiraré las tropas de Europa (Aplausos.)

Le daremos salida al mar a Bolivia (Aplausos.)

Respetaremos las doscientas millas (Aplausos.)

Levantaré el bloqueo de Cuba (Aplausos.)

Haré respetar los derechos humanos (Aplausos.)

Pondré fin a la carrera atómica (Aplausos.) 
Acabaré con la prostitución infantil (Aplausos.)

Con la ayuda de Dios y de Marx

dejaré que florezcan las cien flores (Pifias.)

Reduciré los gastos militares (Pifias.)

La poesía para quien la cultiva

Expropiaremos las cuarenta familias (Rechiflas.)

Instauraré el trabajo voluntario (Aplausos.)

Clausuraré las Cámaras de Diputados y

Todo el poder al pueblo soberano

[Senadores.

Revolución en los EE.UU.

No prometo. Les juro

que volverán los días felices:

Ambigüedad o muerte. ¡Venceremos!

Aplausos atronadores, salvas, fuegos artificiales.

Na-die Na-die Na-die Na-die

Ahora todos a votar por Carter

Ahora todos a votar por Cráter

Ahora todos a votar por Nixon

Ahora todos a votar por Pérez

Ahora todos a votar por González

Ahora todos a votar por Hitler

Ahora todos a votar por Lenin

Ahora todos a votar por el Papa

Ahora todos a votar por mí.

Todos felices a votar por todos

en masa todos a votar por

Nadie.

La banda se desgañita tocando una marcha yanqui. El empresario se acerca al hombre cuando éste se va retirando. Se arma un choclón con todos los del circo que también se acercan. Retiran el lienzo. 
EMPRESARIO: Lo felicito. En serio, lo felicito. Qué bien. Qué buen discurso. ¡Lo felicito! (Todos se pelean por darle la mano y felicitarlo. Varios lo consiguen.) (A sus colegas.) Ya, ya, vuelvan a sus puestos. (A los de la banda.) Ustedes también. (La banda se va a su lugar haciendo sonar sus instrumentos en señal de protesta.) Ya, ya, calladitos: Se acabó el chocloneo aquí. Seguimos trabajando. (Todos se quedan por ahi dando vueltas.) (Al hombre.) Oiga.

HOMBRE: ¿Sí?

EMPRESARIO: ¿Cómo se le portaron los niños?

HOMBRE:

Muy bien. Magnífico. Gracias... Bueno... (Intenta irse.)

EMPRESARIO: No, si son muy buenos para todo. Especialmente para manifestaciones, todo tipo de manifestaciones... Pero aquí le pegamos a todo en realidad. La semana pasada, por ejemplo, nos contrataron como representantes de Peumo en el Dingolondango.

HOMBRE: Ah, ¡qué bonito!

EMPRESARIO: Y hasta yo, fíjese. Yo también me arriendo.

HOMBRE: Ah, ¿sí?

EMPRESARIO:

Claro, igualito que usted.

HOMBRE: ¿Cómo es eso?

EMPRESARIO: Claro... mi especialidad son los discursos. Yo no sólo digo discursos. También escribo discursos para que los digan otros. Psch... Últimamente estoy viviendo de los puros discursos no más. Me ha tocado escribir más discursos que la cresta.

HOMBRE: Ah, qué bueno saberlo...

EMPRESARIO: Oiga, y hablando aquí entre nosotros, ¿cómo ve la cosa usted?

HOMBRE: ¿Qué cosa?

EMPRESARIO: No, al hombre, digo yo. ¿Cómo lo ve? ¿Usted cree que podrá ganar acá el señor...? 
HOMBRE: $\quad$ Fijo.

EMPRESARIO: ¿Fijo?

HOMBRE: $\quad$ Fijo...

EMPRESARIO: Pero, ¿fijo, fijo?

HOMBRE: Fijo, fijo.

EMPRESARIO: $\quad$ Ah... porque yo... me gustaría... yo tengo algunos problemitas.

HOMBRE: $\quad$ Pero, ¿de qué se preocupa? Dígame no más. ¡Cuál es el problema! (Saca una libreta para anotar.)

EMPRESARIO: $\quad$ Bueno, el más importante que tenemos acá es este asunto. (Señala las cruces.)

HOMBRE: ¡Cómo! ¿Qué pasa?

EMPRESARIO: No, es que nosotros estamos instalados aquí y aquí al lado está este cementerio... y esa cuestión va creciendo, pues. Dicen que tienen mucha demanda... Usted ve, mire, ya se están metiendo para acá.

HOMBRE:

¿Pero usted no estará arrendando la carpa para eso también?

EMPRESARIO: ¡Cómo se le ocurre señor! Si eso es justamente lo que nos tiene cagados aquí...

HOMBRE: $\quad$ Pero esto no puede ser, pues hombre...

EMPRESARIO: $\quad$ Eso es lo que yo digo, pero me dicen que ellos tienen que satisfacer las necesidades. Que están obligados a cumplir su deber social... Y ahora quieren que nosotros nos vayamos de aquí.

HOMBRE: ¿Y por qué no se van?

EMPRESARIO: Y ¿cómo?, ¿a dónde? y ¿con qué? Si nos ha ido como las huevas, oiga.

HOMBRE:

Mire, no se preocupe. Yo voy a hablar personalmente con el candidato. Yo le prometo que Nadie va a solucionar este problema.

EMPRESARIO: Muchas gracias. Usted ve que nosotros no hemos tenido inconveniente para que usted hiciera sus cosas aquí.

HOMBRE: Un gesto inolvidable... Bueno, hasta lueguito ¿no?... Muchas gracias. Agradézcale de mi par- 
TONY:

te a toda su gente (Inicia el mutis y un tony lo detiene.)

HOMBRE:

Oiga, señor...

TONY:

Dígame, no más...

Perdone $i$ ah?

HOMBRE:

Con toda confianza. Estamos entre amigos. Rapidito, sí, porque estoy apurado...

TONY:

Es una cuñada mía que tenía una casita...

EMPRESARIO:

Ya, pues, señores, vamos a seguir el ensayo.

TONY:

Ya, voy altiro... (Sigue hablándole al hombre durante todo el desfile. Es una larga tragedia que no se escucha.)

EMPRESARIO: Bueno, todos a sus puestos: (A la banda.) ¿Listos? Ya, empezamos. ¿Se acuerdan cómo era la cosa? (Redoble.) Y la participación de los payasos Matita, Polito y Pitito.

El empresario toca el silbato y la banda irrumpe con la marcha. Desde la boca del tony entra el desfile del circo, vestido cada uno de acuerdo a su trabajo circense. Una vez que termina el desfile entra el librea y tiende el alambre del equilibrista de manera que cruce la pista.

HOMBRE:

(Al payaso que lo ha acompañado en un costado durante todo el desfile.) No se preocupe. Yo lo tengo todo aquí. (Se señala la sien con un dedo.) No se preocupe. Hasta lueguito. (Sale.)

TONY 2: $\quad$ Yo tenía un asuntito, también me gustaría contárselo...

El hombre se arranca y el payaso lo persigue.

EMPRESARIO: (En solemne tono de función.) Y ahora con ustedes respetable público, el equilibrista XX con su juego de gran altura... ¡Un gran especialista de la cuerda floja!

Entra el equilibrista y hace su número. La banda lo acompaña con una música ad hoc. Durante el trabajo del equilibrista los obreros invaden 
gran parte de la pista con sus cruces. Termina el número del equilibrista y éste saluda y sale.

EMPRESARIO: (Mientras el librea retira el alambre del equilibrista.) Ya ven, señoras y señores, como yo tenía razón. El joven equilibrista $\mathrm{XX}$ es un magnífico exponente de la cuerda floja. Lo que no es raro, ya que ésta es una especialidad que ha alcanzado un alto grado de desarrollo en nuestro país.

El empresario anuncia a continuación la actuación del malabarista. Junto con el anuncio, desde la entrada del público, entra un cortejo fúnebre compuesto por el mismo personal del circo disfrazados de dolientes, cura, etcétera, portando flores, coronas, velos negros. El malabarista sale a hacer su número. El cortejo se desplaza desde la entrada por uno de los pasillos laterales hasta ingresar a la pista. Al hacerlo, el empresario se suma al cortejo. Antes se ha puesto unos lentes oscuros y una cinta negra en el brazo izquierdo. Llegan a una de las tumbas y es el propio empresario el encargado de pronunciar el discurso fúnebre. Éste podría contener algunas rimas alusivas de Gustavo A. Becquer (“'Dios mío, qué solos se quedan los muertos!” por ejemplo.) u otro poema altamente funerario. Al promediar el discurso, entra un señor con una enorme maleta que abre e instala sobre una silla de totora en el centro de la pista. Saca mercaderías que cuelga en algunas de las cruces. Cuando el discurso termina, el verdadero deudo saca una billetera y le paga al empresario sus servicios.

EMPRESARIO: $\quad$ Pero esto no es lo que habíamos acordado.

DEUDO: $\quad$ No tengo más... (Intenta irse.)

El empresario y el resto del cortejo lo agarran a palmetazos. El deudo saca su propia palmeta y se defiende a palmetazo limpio hasta que logra huir.

EMPRESARIO: Ustedes me dijeron que era una persona responsable, buena pagadora... 
TONY:

EMPRESARIO:

OTRO:

EMPRESARIO:
¡Cómo! Usted tiene la culpa. Usted dijo que era amigo suyo...

¡Esto es el colmo! ¡Yo tengo que hacer todo aquí!

(Le da un palmetazo al empresario.) ¡Usted no sirve para nada!

(Le devuelve el palmetazo.) Ustedes tienen la culpa....

Todos se culpan con todos de la deshonestidad del deudo y se dan de palmetazos surtidos. Atraviesan la pista, peleando. El hombre de la maleta se llamará "Contrabandista".

CONTRABANDISTA: Ya, pues, niñitos... ya, pues... no nos hagamos los lesos... vamos poniéndonos... si el fiado no es regalado... Saltarín se llamaba el profeta.

La gente detiene la pelea que tenían entre ellos y salen a cambiarse de ropa. Llegan los de la banda.

CONTRABANDISTA: Tú, trompeta. (Busca en su libreta.) Trompeta, trompeta... son... aquí: cincuenta lucas. (Le pagan.) Ya, te van quedando cincuenta más. ¿Vas a llevar algo? (El trompeta niega con la cabeza y se va a los otros.) No me manoseen la mercadería. (Al bombo.) Lo tuyo son... a ver, bombo... bombo... aquí está. Tsch, ésta es la última cuota tuya. ¡Ya! Treinta luquitas y estamos a mano. (El bombo las paga.)

Llega un mendigo de luengas barbas y cabellera blanca, vestido de blanco, con una ropa que recuerda la de los campesinos rusos de la época de los zares, y empieza a rondar la maleta del contrabandista.

CONTRABANDISTA: (Corre al mendigo a patadas.) Ya, ya, córrete de aquí peliento. Me venís a mosquear las cosas.

MENDIGO: dái trayendo... 
EMPRESARIO: (Al entrar se encuentra con el mendigo y le pega una chuleta en el poto.) Partiste, mierda...

MENDIGO: $\quad$ Buena, oh...

EMPRESARIO: $\quad$ ¡Ya, partiste!

MENDIGO: $\quad$ iYa le pagué la comisión por trabajar acá!

EMPRESARIO: Psch, me voy a hacer rico con tu comisión.

Mientras tanto el contrabandista ha arreglado cuentas con los otros músicos.

MENDIGO: ¿No te pagué, no te pagué?

EMPRESARIO: ¡Cállate, mierda! (Le pega otra chuleta y el mendigo arranca.)

MENDIGO: (Desde lejos.) Le tienen que pagar, todavía, para trabajar aquí... la cagada de carpa... no viene nadie...

EMPRESARIO: $\quad$ Medio trabajito, flojo de mierda... anda a pedir limosna al centro a ver si te van a aguantar.

El mendigo sale.

EMPRESARIO: (Al contrabandista.) ¡Qué tiempo que no lo veía por aquí hombre!

CONTRABANDISTA: Sí, es que, puf, está muy difícil la cosa, oiga... muy jodido, jodido, jodido... muy jodido para el contrabando.

EMPRESARIO: ¿Ah, sí, ah?

CONTRABANDISTA: Claro, no ve que ahora todo el mundo puede traer cualquier cosa... Así es que yo obligado a vender estos artículos que no los vende nadie más porque es muy peligroso... Por eso se ha perdido interés en estos artículos... Incluso se ha perdido interés en fabricarlos... muchas de estas fábricas ya cerraron ya...

EMPRESARIO: ¿Ah, sí, ah? Bueno, ¿y cuánto le estoy debiendo yo?

CONTRABANDISTA: A ver... ciento cincuenta...

EMPRESARIO: Pero descuénteme el derecho de venta acá en el local. 
CONTRABANDISTA: Bueno, eso son cincuenta...

MAJORETTE: ¡Qué lindas estas medias!

CONTRABANDISTA: Sí, son Laban, no me las manosee, sí.

El empresario y el contrabandista se pagan mutuamente. El empresario se guarda diez y le pasa los otros cuarenta a uno de los tonys.

EMPRESARIO: $\quad$ El XX tiene la plata del amigo acá. ¡Son cuarenta lucas! (El tony reparte la plata entre los demás.) Bueno, y itrae alguna novedad?

CONTRABANDISTA: Jabón le traigo... Rococó que es el que a usted le gusta.

EMPRESARIO: ¿YY a cómo el Rococó?

CONTRABANDISTA: A diez...

EMPRESARIO: $\quad$ Puta, pero si el Camay está a ocho...

CONTRABANDISTA: ¿No ve, no ve? Hasta usted está convencido de que esto no sirve... No puede comparar, el Camay es americano... Cigarrillos también le traigo, los que a usted le gustan...

EMPRESARIO: ¿A ver?

CONTRABANDISTA: (Saca un cartón.) Hilton, pues jefe... King Size con filtro...

EMPRESARIO: $\quad$ Bueno, deme uno. (El contrabandista le pasa el cartón.) No, yo quiero una cajetilla, no más.

CONTRABANDISTA: No, esto se vende por cartón no más. Si está muy jodido entrar estas cosas, oiga... Si ya la cuestión no es como antes. Para los productos chilenos la cosa se ha puesto muy pesada. Antes, esto lo encontraba usted en cualquier lado, pero eso ya pertenece a la historia. Si es chileno, es bueno, se decía, acuérdese usted, pues...

TONY: $\quad$ Oiga y para el... (Hace gesto de tomar.) ¿No trae nada?

CONTRABANDISTA: Claro, le traigo Carola una estrella. Este es un vino de exportación allá...

TONY: ¿Y a cuánto?

CONTRABANDISTA: Éste le sale... a 15 la botella. 
TONY: $\quad$ Muy caro... ¿Y algo más barato?

CONTRABANDISTA: Bueno, la garrafa de Cunaco que le sale a 35 .

TONY: Bueno, anóteme una garrafa. (Se lleva la garrafa.)

EMPRESARIO: $\quad$ Pucha que está carero, iñor.

CONTRABANDISTA: Bueno, yo le digo, no más... Aproveche ahora, porque después estas cuestiones van a desaparecer. Por ejemplo, aquí tiene una Sindelita... Esta cuestión va a cagar y después no la va a encontrar ni con un cabo de vela y usted me va a venir a decir "deme una Sindelita" y yo le voy a tener que decir "cagó la Sindelita". Así es que yo le aconsejo, $i$ ah? No es por hacer negocio, porque a mí me pelean en otras partes, pero si puede comprarla ahora le diría "Cómprela".

EMPRESARIO: $\quad$ Bueno, ya, démela. Anótemela.

CONTRABANDISTA: Claro, no se va a arrepentir, porque yo aquí también le tengo una Yamimotonocamina, pero esta cuestión es japonesa, no más. Yo gano más plata con ésta, pero no lo voy a estar engañando a usted.

EMPRESARIO: $\quad$ No, no, si deme la Sindelita, no más... Anótemela. ¿Y para los niños? ¿Trae algo?

CONTRABANDISTA: Para los cabros chicos tengo cuestiones muy lindas. Juguetes muy novedosos. Por ejemplo, aquí tiene un remolino. (Lo saca.) Usted sopla esta cuestión y comienza a dar vueltas. Mire. (Lo hace.) Ahora puede correr así y mire, mire. (Lo hace.) Y este otro, mire. (Saca un emboque y lo hace funcionar.) ¿Ve? Este se llama emboque. Puede jugar a lo hombre. Así. (Lo hace.) O a lo mujer. Así. (Lo hace.) Puede jugar simple. Así. (Lo hace.) O doble. Así, ¿ve? (Lo hace.)

EMPRESARIO: $\quad$ Ah, esto me lo voy a llevar, también. (Se pone a jugar.)

TONY: ¿Y este otro?

EMPRESARIO: Ah, ése es un trompo... 
TONY: $\quad$ Ah, si yo me acuerdo de estas cuestiones. (Lo hace bailar.)

CONTRABANDISTA: Estos vienen siendo los últimos, ya no se fabrican más.

EMPRESARIO: $\quad \mathrm{Y}$, ¿qué pasó con estas cosas, oiga?

CONTRABANDISTA: Yo era operario en la fábrica de trompos, antes que la cerraran, así que sé muy bien lo que pasó. El dueño nos dijo: "Voy a tener que cerrar, porque no tengo mercado para vender porque la gallada anda sin pega y sin plata". Así es que cerró la fábrica y nos echaron a todos ahí, y parte del desahucio me lo pagó en trompos. Después liquidó todo y metió la plata que le quedaba a interés, en el mercado de capitales, que le dicen.

EMPRESARIO: Claro, si eso es lo único que se puede hacer. ¿Para qué se va a andar callampiando usted con sueldos, leyes sociales y todas las gabelas?

CONTRABANDISTA: Pero así va a cagar todo y menos pega y menos plata va a tener la gallada, pues, iñor...

EMPRESARIO: Así tiene que ser, pues... Como en EE.UU.: el que caga, caga.

CONTRABANDISTA: Lo único que le falta es que se me ponga a hablar en inglés, ahora.

EMPRESARIO: ¿Y por qué no? La media dificultad... What are you talking about? (Todos se ríen.)

CONTRABANDISTA: Ya veo lo que diría si le trajeran un circo de EE.UU.

EMPRESARIO: Que traigan, que traigan. Aquí estamos para enfrentar la competencia.

CONTRABANDISTA: Y ¿esto? ¿También lo va a traer de EE.UU.? (Saca un disco.)

EMPRESARIO: ¿Qué es eso?

CONTRABANDISTA: (Lee la carátula.)

En el centro de la mar suspiraba una guitarra y en el suspiro decía que cante Violeta Parra 
EMPRESARIO: Bah, y todavía quedan de estas cuestiones. ( $\mathrm{Al}$ tony.) A ver póngase este disco.

El tony sale a poner el disco.

CONTRABANDISTA: Claro, si eso es indestructible. ¿No ve que no es nada una fábrica de trompos? Contra eso se rompe la cabeza cualquiera... Eso es firme como un peral. Es como el cerro San Cristóbal. ¿No ve que eso todos los chilenos lo llevamos aquí? (Se señala el corazón.)

Entra el disco de Defensa de Violeta Parra, recitado por Nicanor Parra, por los parlantes. El contrabandista guarda sus cosas y se despide. Se retira y lo van a dejar hasta la puerta y salen todos. La luz va bajando hasta quedar un solo reflector concentrado en la silla de totora, sola en el centro del escenario.

Una vez terminado el disco, entran dos tonys que, con la misma luz, hacen un número con la silla. Salen. Se abre toda la luz y entra el empresario acompañado del poeta, que usa indumentaria de intelectual provinciano.

EMPRESARIO:

POETA:

EMPRESARIO:

POETA:

EMPRESARIO:

POETA:

EMPRESARIO:

POETA:

EMPRESARIO:

TONY:

EMPRESARIO:
(En la pista.) Conforme. Estamos completamente de acuerdo.

Pero que sea un discurso sentido...

No se preocupe. Mi especialidad son los discursos sentidos.

Pero que sea un discurso sentido...

Sí, sí, ya sé, pero acuérdese de que el pago es por anticipado.

No, no, usted dice la primera palabra del discurso y yo le pago.

De acuerdo... Bueno, hasta luego...

Hasta luego. (Inicia el mutis.) Pero que sea sentido... (Sale.)

(Dirigiéndose a la boca del tony, gritando.) ¡Ya pues, niños, sigamos el ensayo!

(Asomando la cabeza por la boca del tony.) Espérese un poquito, nos estamos preparando.

Apúrese porque yo tengo que preparar mi discurso para el banquete de los poetas. 
TONY:

EMPRESARIO:

TONY:
¡Cómo! ¿Cayó una pega?

Claro, ese caballero que se acaba de ir acaba de contratarnos... ¿Están listos ya?

¡Listos, jefe! (Desde adentro, gritando.) ¡Atención Batallón de Pancho Villa! ¡De frente, mamaaar!

Los tres tonys entran y hacen el número de los pasos de una formación militar. Este número es interrumpido por el poeta que entra desde la puerta de público, acompañado por alguna gente que trae consigo los bártulos necesarios para el banquete: mesones, caballetes, mantel, canastos con botellas, cajas con alimento, etcétera.

POETA: $\quad$ Perdone, caballero... (Empiezan a instalar la mesa en la pista.)

TONY: $\quad$ Pero no interrumpa el ensayo, pues señor.

POETA: Perdone, señor Villa, es que yo contraté un banquete acá y...

TONY: $\quad$ Pero eso no es aquí en la pista. Es por allá. (Señala hacia un costado donde hay una tarima.)

Levantan la mesa y todos los demás elementos y los llevan adonde les indicó el tony.

POETA: (Yéndose.) Perdone, caballero.

Los tonys continúan su número mientras se instala la mesa del banquete, que es en " $U$ " cubierta por un mantel de plástico verde floreado sobre el que hay botellas vacías. Durante el número entran los demás miembros del circo disfrazados de gente de la Sociedad de Escritores de Chile.

Los tonys terminan su número y salen. Junto con la salida se enciende la luz en la tarima y la concurrencia baila los últimos compases de un pasodoble que toca la banda. Mientras bailan aparece el mendigo que viene a pedir limosna. Lo echan. Termina el baile y todos toman ubicación en la mesa. El empresario, con sombrero alón y capa española negros, se pone de pie y pide silencio golpeando una copa con un tenedor, y a que todos cantan "Tómese esa copa, esa copa de vino...". 
EMPRESARIO: Agradezco a todos ustedes por la colaboración prestada al brillo de esta manifestación.

Se pone de pie el poeta-arrendador y le pasa un rollo de billetes. Se abrazan. El empresario saca su parte y le pasa el resto al del lado, quien repite la operación.

EMPRESARIO: Agradezco especialmente al señor Presidente de la Sociedad de Mantención del Recuerdo Eterno de los Poetas Muertos y Vivos por haber arrendado nuestros servicios profesionales para ayudarlo a cumplir los elevados propósitos de la institución que tan dignamente preside. (Aplausos. Nuevo abrazo. Toca la copa.) Y en lo personal, agradezco al señor Presidente la oportunidad que me brinda de dirigiros la palabra en este banquete anual con que la Sociedad de Mantención del Recuerdo Eterno de los Poetas Muertos y Vivos da inicio todos los años a su romería a la tumba del poeta desconocido (Aplausos. Todos se abrazan. Toca la copa.) Y para terminar felicito también a los señores bomberos honra y prez de nuestra colectividad se les saluda con la mayor devoción Doy las gracias al Supremo Hacedor en el auspicioso día de su onomástico que la Divina Providencia lo colme de gloria su Affmo. y seguro servidor

Felicito al Cuerpo Diplomático

por la colaboración prestada.

A la prensa - a la radio - a la T.V.

por la colaboración prestada

Agradezco muy en particular a los señores

ellos son nuestros terceros padres

[fotógrafos a los periodistas desinteresados ellos son nuestros padres ubérrimos 
Felicito de todo corazón a nuestros hermanos

[de la gran

República del Norte

que exponiendo sus vidas personales

en beneficio de la humanidad

ponen en jaque a los revoltosos

sin ambiciones de ninguna especie

animados por ese espíritu de sacrificio

de que sólo pueden hacer gala

los espíritus superiores

Por la libre determinación de los pueblos

Por un mundo sin explotadores

El orden público está asegurado.

Ése es el canto del cisne del capitalismo

Bendigo a la flor y nata de la intelectualidad

[chilena

Felicito de todo corazón a los oradores

que me han precedido en el uso de la palabra

Al señor Rector del Liceo de Hombres

A la Srta. Marta Brunet Premio Nacional de

[Literatura

que tuvo la amabilidad de dirigirnos la palabra

Al Director del Diario La Discusión

Al Director Interino de Impuestos Internos

A la Madre Superiora de la Casa Correccional

Felicito de todo corazón

a los ancianos del Instituto de Recuperación

A la Gota de Leche

A los pacientes del Instituto Pedagógico.

Uds. están asistiendo a los funerales del yo

[poético

que reventó por exceso de delicadeza

A depositar una corona de rosas

en la tumba del poeta desconocido.

Salen en romería hacia el cementerio. Mientras el mendigo va pidiendo limosna y todos lo corretean a chuletas. La romería recorre todo el pasillo que separa la platea de la galería. 


\begin{tabular}{|c|c|c|}
\hline \multirow[t]{9}{*}{ EMPRESARIO: } & Manuel Magallanes Moure & Presente \\
\hline & Alonso de Ercilla y Zúñiga & “ \\
\hline & Carlos Pezoa Véliz & “ \\
\hline & Juan Guzmán Cruchaga & “ \\
\hline & Carlos Ibáñez del Campo & “ \\
\hline & Arturo Alessandri Palma & “ \\
\hline & Nicanor Parra & “ \\
\hline & Eusebio Lillo & “ \\
\hline & El que sabemos & “ \\
\hline HOMBRE 1: & El que te dije & “ \\
\hline HOMBRE 2: & El que te jedi & “ \\
\hline HOMBRE 3: & El que se para & “ \\
\hline \multirow[t]{2}{*}{ EMPRESARIO: } & El que la caga & “ \\
\hline & Pablo Neruda & “ \\
\hline MUJER 1: & Gabriela Mistral & “ \\
\hline \multirow[t]{2}{*}{ EMPRESARIO: } & Vicente Huidobro & “ \\
\hline & Pablo de Rokha & “ \\
\hline MUJER 2: & Pastel de Choclo & “ \\
\hline HOMBRE 4: & Malta, Bilz y Pílsener & “ \\
\hline HOMBRE 5: & Me guarda la botella & “ \\
\hline
\end{tabular}

EMPRESARIO: Lomito palta mayo Que corra maestro

Tres de pino y tres de queso "

Completo que sea " "

Manuel Plaza

POETA: $\quad$ Filete mignon champignon Ausente

EMPRESARIO: Roberto Meza Fuentes Presente

MUJER 1: $\quad$ Anita Lizana, poeta de la raqueta

HOMBRE 3: $\quad$ El Sapo Livingstone poeta de la pelota

EMPRESARIO: $\quad$ El Enano Maldito pelota de los poetas “

MUJER 2:

Arturo Godoy poeta de los puñetes “

EMPRESARIO: Óscar Castro Ángel Cruchaga Santa María 
La romería entra a la pista.

EMPRESARIO: Reforma Agraria Presente

Constitución Política del Estado En veremos

Derechos Humanos

Ausente

Humanos Derechos

Presente

Pan, techo y abrigo

Ausente

1, 2, 3 momia

Presente

La romería se coloca alrededor de una tumba en la pista. El poetaarrendador ha colocado una corona encima de la cruz que corresponde. Después del último presente, la romería queda congelada. La irrupción del mendigo los descongela. Éste comienza a dar saltitos y habla. La gente de la romería se coloca alrededor de la pista, escuchándolo.

MENDIGO:

En su granja de Iásnaia Poliana

vivió muchos años el conde León Nicolaievich

[Tolstoi

No se afeitaba jamás - andaba siempre descalzo

Dios lo tenga en su santo reino

Sólo comía zanahorias crudas

Uds. se preguntarán quién soy yo

Con esta barba blanca tolstoiana

pidiendo limosna en la vía pública

ay!... yo soy uno de sus nietos legítimos

La revolución ha sido dura conmigo

para qué voy a decir una cosa por otra

que cada cual me dé lo que pueda

(aquí se empieza a correr el sombrero)

todo me sirve aunque sea un kopek

ay!... si yo les contara todos mis sufrimientos

imaginen al nieto de un conde

pidiendo limosna en la vía pública

¡Es para poner los pelos de punta! 
Además, mi mujer se fue con otro me dejó por un capitán de Ejército so pretexto de que soy paralítico No negaré que soy paralítico ¡Tiemblo como una hoja en la tormenta! Pero me parece que no se puede romper un sacramento de la Santa Madre Iglesia Católica como quién rompe globos de colores: Hay señoras mujeres en el siglo veinte que se debieran desmayar de vergüenza

ay ay ay-ay ay ay-ay ay aycito

Compadézcanse de este pobre cornudo no dispongo de otra fuente de ingreso

Para qué voy a decir una cosa por otra sufro de una enfermedad incurable contraída en la más tierna infancia: Tengo todo el lado derecho paralizado me puedo morir en cualquier momento

Mi enfermedad se llama encefalitis letárgica

Para colmo de males acaban de operarme de la vesícula si les parece les muestro la cicatriz ay... no tengo paz en ninguna parte para qué voy a decir una cosa por otra los pelusas del barrio me persiguen tirándome [piedras hay que ser bien caído del catre para reírse de un pobre viejo zarrapastroso que no tiene ni dónde caerse muerto Si mi querido abuelo estuviera vivo yo no tendría que andar pidiendo limosna ¡otro gallo muy diferente me cantaría! 
Dicho sea de paso tengo que juntar diez y siete

[dólares

antes que me venga el ataque

para pagar mi dosis de heroína

A buen entendedor pocas palabras

Si no me dan por la buena

Van a tener que darme por la mala

Para qué vamos a decir una cosa por otra

Yo soy bien hombrecito en mis cosas

Arriba las manos maricones de mierda

vamos saltando o les saco la chucha

Saca un cuchillo y amenaza a los de la romería. Suena un balazo y el mendigo, lanzando un chorro de sangre por la boca que lo mancha entero, se da varias vueltas por la pista sembrando el pánico, el desconcierto y la sangre por los cuatro puntos cardinales. Cuando se le termina su propia sangre va a buscar un lavatorio lleno de sangre que la reparte por todos lados. Al fin cae muerto. La romería arranca. Un tony que se ha quedado solo saca el cadáver haciendo el número de payaso "el muerto vivo" y cuando logra sacarlo la banda lo acompaña con un galope. Los de la romería han regresado y aplauden el éxito del tony. Lo aplauden, se enjuga el sudor del susto y del esfuerzo. En eso están cuando hay un cambio de luz. La música se hace siniestra y entra un fantasma. Luego entra un segundo fantasma. La romería huye. Los fantasmas se rien: son los dos tonys disfrazados.

Se sacan el disfraz y hacen un número. Mientras los tonys hacen su número entra la señora del deudo del cortejo fúnebre y llorando se acerca a la tumba de su pariente supuesto y se queda allí. Luego entra un poeta y se queda recitando como malo de la cabeza, frente a la tumba de la romería. Después aparece la novia acompañada del monaguillo $y$, acompañados por la trompeta que toca una fúnebre marcha nupcial, se instalan frente a una de las tumbas. Una vez terminado el número de los tonys, entra el empresario a hacer otro anuncio.

EMPRESARIO: (Impresionado por el espectáculo con que se encuentra.) Y ahora, señoras y señores voy a dejar con ustedes a un dúo cómico de extraordinaria 
calidad que representará para ustedes una nueva astucia con que el guerrillero Manuel Rodríguez hace leso al Capitán de Talaveras don Vicente San Bruno. (Sale.)

Se escucha el galope de un caballo que se detiene. Entra un actor disfrazado de Manuel Rodríguez.

RODRÍGUEZ: Guerrillero Manuel Rodríguez

me llaman en este lugar.

Soy un verdadero patriota

que quiere al pueblo liberar

de las cadenas que los godos

nos han impuesto sin piedad.

Para eso necesito armas

y aquí me las he de robar

Vengo junto con mis leales

a este cuartel a asaltar

que está repleto de cañones

De fusiles hay un millar;

Para el caso usaré la astucia

que es mi método principal.

Por eso estoy así vestido

y no me ven de militar.

Con esto engañaré a San Bruno

de este cuartel el Capitán.

Quien no podrá reconocerme

debajo de este hábil disfraz.

Cuento también para esta empresa

con que bebe como animal.

Seguro que llega achispado

y muy fácil de cazuelear.

Pasaré por Cabo de Guardia

y le robaré el arsenal.

Entra el empresario

EMPRESARIO: (Interrumpiendo.) No, no, no, esto no se puede hacer... 
RODRÍGUEZ:

EMPRESARIO:

RODRÍGUEZ:

EMPRESARIO:

RODRÍGUEZ:

EMPRESARIO:

RODRÍGUEZ:

EMPRESARIO:

RODRÍGUEZ:

EMPRESARIO:

RODRÍGUEZ:

EMPRESARIO:

RODRÍGUEZ:

EMPRESARIO:

RODRÍGUEZ:

EMPRESARIO:

RODRÍGUEZ:

EMPRESARIO:

RODRÍGUEZ:

EMPRESARIO:
(Rompiendo su personaje.) Pero, ¿por qué?

Porque no y punto...

¿Y quién dice que no se puede hacer?

Yo digo y se acabó...

Bueno, pero si no ensayamos esta cuestión va a salir como las reverendas.

Cómo se le ocurre ponerse a ensayar ese tipo de número aquí en medio de un cementerio...

Pero, ¿qué tiene? Si lo hemos hecho tantas veces...

Pero no aquí. Usted tiene que tener respeto por el dolor ajeno.

Bah, ahora se puso a defenderlos a ellos...

Yo no defiendo a nadie, señor, pero no se puede hacer...

¿Y cómo permitió a los otros?

Ésa es otra cuestión, pero esa cancioncita que ustedes cantan ahí, no puede ser...

¿Cuál? ¿Ésa que canto yo? Ésa... los pollitos dicen pío, pío, pío cuando tienen hambre, cuando tienen frío...

No, sabe perfectamente que no es ésa... no se venga a hacer el de las chacras.

Ah, usted dice la de Palito Ortega... Ésa. (Canta también.) La felicidad, ah, ah, ah, ah; de sentir amor oh, oh, oh, oh.

¡Esa, pues, jetón! ¿Te parece poco ponerse a cantar esa cuestión aquí?

Pero, ¿por qué?

Ya, se acabó el ensayo.

(Yéndose.) Bueno, usted sabrá... yo no sé...

(A todos.) Ya, se acabó el ensayo... por hoy se acabó el ensayo, seguimos mañana. Por hoy quedamos hasta aquí. Yo no puedo seguir tratando de sacar esto adelante entre puros muertos y payasos irresponsables. ¡Ya! Se acabó el ensayo, mañana seguimos, se acabó el ensayo. (Sale.) 
Desde su entrada y sin interrupción ninguna los personajes que están en el cementerio han seguido: la señora, llorando; la novia, botada sobre la tumba sollozando; el trompetista tocando su música al lado de ella; el poeta, recitando sus versos. Con los últimos gritos del empresario entran, uno a uno, todos los números del circo, otros deudos, el contrabandista a ofrecer su mercadería. Con la salida del empresario comienza a oírse, muy bajito por los parlantes, una música de organillo que va subiendo poco a poco. Junto con la entrada de la malabarista, el resto de la banda la acompaña con la música de su número. Cuando está todo el elenco en escena y la música alcanza su máximo volumen, se corta la luz quedando solo los spots azules y todos se detienen como en un cuadro. La música se corta de golpe. Entre la gente paralizada (el trapecista cuelga de los pies en su trapecio.) Entran vestidos de calle el actor que hizo el empresario y el actor que hizo el discurso de "Nadie" y "El mendigo". Traen sendas copas de vino en sus manos y dicen entre los dos:

ACTOR 1: $\quad$ Lo queramos o no

Sólo tenemos tres alternativas

El ayer, el presente y el mañana.

EMPRESARIO: $\quad$ Y ni siquiera tres

Porque como dice el filósofo

El ayer es ayer

Nos pertenece sólo en el recuerdo:

A la rosa que ya se deshojó

No se le puede sacar otro pétalo.

ACTOR 1: $\quad$ Las cartas por jugar

Son solamente dos:

El presente y el día de mañana.

Y ni siquiera dos

Porque es un hecho bien establecido

Que el presente no existe

Sino en la medida en que se hace pasado

Y ya pasó...,

como la juventud 
352

EMPRESARIO: $\quad$ En resumidas cuentas

Sólo nos va quedando el mañana:

Yo levanto mi copa

Por ese día que no llega nunca

Pero que es lo, único

De lo, que realmente disponemos.

Se beben la copa de vino y se apaga la luz.

FINAL 